\title{
Life-cycle and population dynamics of Rhincalanus gigas (Copepoda: Calanoida) in the Scotia Sea
}

\author{
G. A. Tarling*, R. S. Shreeve, P. Ward \\ British Antarctic Survey, Natural Environment Research Council, High Cross, Madingley Rd, Cambridge CB3 0ET, UK
}

\begin{abstract}
A stage- and age-structured model was constructed to simulate stage-abundance patterns of Rhincalanus gigas in a data set consisting of over $80 \mathrm{yr}$ of net-catch observations in the Scotia Sea. The model was initialised with the observed annual abundances of the CI stage and the population developed according to pre-defined developmental stage durations, which varied according to life-cycle phenotype. Better fits to net-catch observations were achieved by models that allowed a number of different life-cycle phenotypes to co-exist in the population. In particular, a model in which $71 \%$ of individuals reached adulthood in $2 \mathrm{yr}$ ( 2 yr phenotype) and $29 \%$ in $1 \mathrm{yr}$ ( 1 yr phenotype) achieved the best fit. Of the $2 \mathrm{yr}$ phenotypes, most individuals spent their 1st winter as a CIII, although a fraction passed this period as a CIV or CV. The $1 \mathrm{yr}$ phenotypes entered their 1st winter as a CV but moulted through to adulthood before the following spring. During the productive period, the mortality rate of the early developmental stages was $0.1 \mathrm{~d}^{-1}$, but this fell to $0.007 \mathrm{~d}^{-1}$ as individuals developed beyond stage CIII. During the winter, the mortality rate fell further to $0.003 \mathrm{~d}^{-1}$. Such rates meant that around $1.5 \%$ of the copepodite population lived for $3 \mathrm{yr}$ or more. Many of these spent $2 \mathrm{yr}$ as an adult. Quantitative descriptions of development and mortality rates in the later stages of long-lived copepods are relatively few because of the difficulty in distinguishing the many generations in a typical population. As well as being the first to determine these rates in R. gigas, this study provides a methodological framework for determining such rates in other copepods with multi-year life cycles.
\end{abstract}

KEY WORDS: Copepod ' Zooplankton - Southern Ocean · Phenotype - Diapause - Mortality · Development $\cdot$ Stage-structured model

\section{INTRODUCTION}

Rhincalanus gigas is one of the principal species of the Southern Ocean copepod community (Ommaney 1936). It is particularly common in the Scotia Sea, where its biomass peaks in the vicinity of the Polar Front (Ward et al. 1997). The species mainly consumes phytoplankton (Schnack et al. 1985, Atkinson 1994, Atkinson et al. 1996) but there is evidence of some degree of omnivory (Graeve et al. 1994) and detrital feeding (Arashkevich 1978). Although $R$. gigas does not perform significant diel vertical migrations (Mackintosh 1937, Chojnacki \& Węglénska 1984), it does exhibit a seasonal descent, migrating from the top $100 \mathrm{~m}$, where it spends most of the summer months, to between 250 and $1000 \mathrm{~m}$ in the winter (Ommaney
1936). Activity levels probably drop during winter, but it is unlikely that the species enters a true state of diapause during wintertime since it has neither the large lipid reserves, nor the lower respiration rates (Pasternak et al. 1994, Hagen \& Schnack-Shiel 1996), that are found in true diapausing species at that time of year (Hagen \& Schnack-Shiel 1996). Gonad maturation and egg production are food limited (Ward \& Shreeve 1995, Ward et al. 1996), which may be why the species spawns sporadically through a large part of the year (Atkinson 1991, Bathmann et al. 1993). Nevertheless, it is believed that most recruits result from the spawning peak in midsummer (Ward et al. 1997).

Observed stage abundance patterns of Rhincalanus gigas are difficult to interpret. It is recognised that there is an overlap in generations, since total abun- 
dances do not show large oscillations between seasons and there are usually 3 developmental stages present at any one time (Atkinson 1991). The relative dominance of different developmental stages changes with time of year, but there is considerable variability in these patterns between years and between subregions (Ward et al. 1997). The lack of an easy method to track the development of the population means that the derivation of growth and mortality rates has rarely been attempted, particularly in the latter developmental stages.

There have been a number of attempts to describe the life cycle of Rhincalanus gigas through qualitative analysis of population data. Ommaney (1936) concluded that the species spawned twice a year, the 2nd spawn being in winter. This interpretation was criticised by Voronina (1970) on the grounds that it was unlikely that the winter-spawned generation would survive the period of food shortage. Alternatively, she proposed that the life cycle lasted 1 yr. However, this did not explain the characteristic features of overlapping generations apparent in the stage abundance patterns. Marin (1988) proposed that a 2 yr life cycle produced a better fit to observations, while Atkinson (1991) suggested that low larval mortality rates and highly staggered spawning periods would create an overlap of generations in a population made up of individuals with a 1 yr life cycle. Ward et al. (1997) proposed that there was a mixture of possible life cycles in the population and that individuals exhibiting $1 \mathrm{yr}$ and 2 yr life cycles may co-occur.

These semi-opposing views illustrate that the interpretation of stage and abundance datasets is complex when there is an overlap in generations, as is common in many polar copepod species. As a result, there are very few reliable population-level estimates of development times and mortality rates in such species, particularly for the later developmental stages. The need to derive robust estimates of these parameters is becoming ever more apparent, given our increasing understanding of the importance of zooplankton to biogeochemical processes in polar regions (Pakhomov et al. 2002, Dagg et al. 2003, Suzuki et al. 2003)

In this study, we take a quantitative modelling approach to estimate the most likely composition of different life-cycle phenotypes in the Scotia Sea population of Rhincalanus gigas. We advance our interpretation of the complex population dynamics of this species through minimising the degree of subjective interpretation that has been necessary in the past. As a result, we make the first derivation of population level development and mortality rates of this species over its entire life cycle. Furthermore, the types of life cycles exhibited by this species and their relative prevalence within the Scotia Sea population are identified. At a more general level, by demonstrating the successful application of this quantitative approach, we illustrate how similar levels of precision in the measurement of development and mortality can be achieved for other long-lived copepod species.

\section{MATERIALS AND METHODS}

Determination of life-cycle phenotypes. A first approximation of the potential life-cycle phenotypes that may exist in the Scotia Sea population of Rhincalanus gigas can be obtained through combining information on developmental times and seasonal net-catch observations. Shreeve et al. (2002) made direct measurements of the stage durations of CI and CII, which lasted a combined total of $29 \mathrm{~d}$ in the Scotia Sea. Similar measurements on the naupliar stages have not been made but can be inferred through reference to the congener Rhincalanus nasutus, where these stages last around twice as long as the combined duration of CI and CII (Hart 1990). This amounts to around $60 \mathrm{~d}$ for $R$. gigas in the Scotia Sea. Ward \& Shreeve (1998) estimated that egg-hatching times are around $7 \mathrm{~d}$ at the average Scotia Sea temperature of $2^{\circ} \mathrm{C}$. Therefore, to develop from egg to CIII would take this species a total of $96 \mathrm{~d}$ in the Scotia Sea. Despite considerable variability in the duration of the productive season in the Scotia Sea (Korb et al. 2004), Longhurst (1998) proposed that it lasted an average of $4 \mathrm{mo}$, based on a large-scale temporal and spatial synthesis of satellite-derived productivity data. An individual $R$. gigas spawned in the earlier part of this period would therefore be fully capable of reaching stage CIII within this time.

Stages CIII and beyond are all common components of the overwintering population (Ward et al. 1997), meaning that the population must contain a variety of life-cycle phenotypes. Two phenotypes that can readily be identified from the observations of Ward et al. (1997) are ones in which: (1) the 1st winter is spent as a CIII stage, and (2) the 1st winter is spent as a CIV stage. Spending the 1 st winter as a stage $\mathrm{CV}$ also seems feasible given the observations of R. S. Shreeve (unpubl.) of CIV individuals moulting to CV in autumn. The moult from CV to adulthood occurs exclusively in the late winter to early spring (Ward \& Shreeve 1999, Shreeve et al. 2002), so the only individuals likely to reach adulthood within $1 \mathrm{yr}$ are those that enter their 1st overwintering period as a CV. Even so, some of these individuals may take another 12 mo before making this final moult, becoming an adult at a similar time to those individuals that spent their 1st winter in stage CIII or CIV. The possibility of these individuals taking 
a further $2 \mathrm{yr}$ to reach adulthood also cannot be excluded. On becoming an adult, an individual may survive for at least another year given that the development of new ovaries on top of old has been observed (R. S. Shreeve pers. obs).

We summarise the variety of potential developmental paths to adulthood in Table 1. In the 1st year, individuals may spend their 1st winter as a CIII, a CIV or a CV. During that winter, some CV individuals moult through to adulthood (CV 1 yr phenotype) while others wait another complete year before doing so (CV 2 yr phenotype). Many individuals spending their 1st winter as CIII or CIV are likely to moult to adulthood after another 12 mo (CIII 2 yr and CIV 2 yr phenotypes respectively). However, it is possible that certain individuals may take a further year to reach adulthood, particularly if they spent their 1st winter in CIII (CIII 3 yr phenotype). The lifespan of the females is indeterminate and may span more than $1 \mathrm{yr}$, depending on the prevailing mortality rate.

Population modelling. Relating models to observations: To determine the relative proportions of the possible life-cycle phenotypes in the population, we adopted a fitting procedure of the kind employed by Tarling et al. (2004) in the analysis of the population dynamics of Calanoides acutus. The procedure compares data generated by model runs to seasonal netcatch observations of stage abundance. The goodnessof-fit of each model run is determined through leastsquares regression analysis. Both the relative proportion of different life-cycle phenotypes and the mortality rate are altered systematically in each model run. Once all runs are complete, the respective levels of fit are ranked in order to identify the best fitting combination of mortality rate and life-cycle phenotype composition.

Net catch observations: The observed stage abundance dataset was the same as described in Ward et al. (1997). Briefly, this included published and unpublished data on abundance and developmental stage structure of Rhincalanus gigas in the $0^{\circ}$ to $80^{\circ} \mathrm{W}$ sector which met the following criteria: (1) all hauls had to be carried out in water depths exceeding $1000 \mathrm{~m},(2)$ nets were fished to $1000 \mathrm{~m}$, (3) mesh sizes were $200 \mu \mathrm{m}$ or smaller. Ward et al. (1997) divided the sector into 3 regions: Northern (which covered most of the Scotia Sea), Weddell-Scotia Confluence, and Eastern Weddell Sea. The latter 2 regions are considered to be at the southernmost fringes of the distribution of this species (Ward et al. 1997) where the completion of the life cycle is likely to be a struggle. We focus only on the Northern region since it contains the most complete coverage of stages and seasons and is where the full range of life cycles are most likely to be expressed. Data were considered in terms of integrated abundance (ind. $\mathrm{m}^{-2}$ ) between 0 and $1000 \mathrm{~m}$. We assumed that none of the population goes below $1000 \mathrm{~m}$ at any time of year, based on Ommaney (1936).

Mortality rates: It is difficult to ascertain the mortality rates of developmental stages containing a number of year-classes in copepod species that do not exhibit continuous recruitment. It is for that reason that this modelling approach must fit mortality rates alongside the composition of life-cycle phenotypes. However, it is not necessary to fit mortality rates over the entire life cycle because there are certain phases where direct approximation becomes possible. We identified 2 such phases: (1) during overwintering and (2) in the early developmental stages, CI and CII.

(1) Overwintering mortality: Recruitment into the latter copepodite-stage population (CIII and beyond) during the overwintering period is negligible. Therefore any decline in the total number of individuals in these stages over that period is a good approximation of the prevailing mortality rate. Ward et al. (1997) determined the change in numbers of the overwintering population through synthesising net catch abundances taken during the autumn, winter and spring in the Scotia Sea from a variety of sources. They found there was a significant decline in the population over this time, with a coefficient of -0.003 . This rate of decline was applied to all developmental stages that entered the overwintering period in the model.

Table 1. Rhincalanus gigas. Potential life-cycle phenotypes in Scotia Sea population showing the developmental stages attained at certain key points in the life history

\begin{tabular}{|lllcrrr}
\hline \multirow{2}{*}{$\begin{array}{l}\text { Days since } \\
1 \text { Aug }\end{array}$} & $\begin{array}{c}\text { Key point } \\
\text { in life history }\end{array}$ & CV 1 yr & CIII 2 yr & Phenotype & \\
\cline { 3 - 4 } & CIV 2 yr & CV 2 yr & CIII 3 yr \\
\hline 212 & Start of winter 1st yr & CV & CIII & CIV & CV & CIII \\
458 & End of winter 1st yr & Adult & CIII or CIV & CIV or CV & CV & CIII or CIV \\
577 & Start of winter 2nd yr & Adult & CV & CV & CV & CV \\
823 & End of winter 2nd yr & Adult & Adult & Adult & Adult & CV \\
942 & Start of winter 3rd yr & Adult & Adult & Adult & Adult & CV \\
1188 & End of winter 3rd yr & Adult & Adult & Adult & Adult & Adult \\
\hline
\end{tabular}


(2) Early stage mortality: It is possible to determine the mortality rate of a specific developmental stage when recruitment is pulsed and stage duration has been determined independently. Ward \& Shreeve (1999) and Shreeve et al. (2002) derived stage durations of CI (11 d) and CII (18 d), which they found to be relatively inflexible. Accordingly, mortality rates of these 2 stages can be deduced using a stage and age structure model (SASM) as follows:

$$
N_{t+1, \text { age }+1}=N_{t, \text { age }} \mathrm{e}^{-\beta \times t}
$$

where $N=$ number of individuals and $t=$ time. The model was initialised with the observed annual stage abundances of $\mathrm{CI}$, which was smoothed using a weighted-average function. Assuming that these individuals were, on average, mid-way through the CI stage, development into CII occurred after only onehalf of the full stage duration of $11 \mathrm{~d}$ had passed (this was rounded up to the nearest integer of $6 \mathrm{~d}$ ). The subsequent CII stage lasted a further $18 \mathrm{~d}$. At the end of the model run, the numbers of individuals within the designated ages of CI and CII were collected for each day as follows:

$$
N_{t, \text { stage }_{x}}=\sum N_{t, \text { age }}
$$

The model was compared to observations through determining the sum of squares difference (SS) between predicted (pre) and observed (obs) values:

$$
\mathrm{SS}=\sum\left(N_{\text {pre, }_{\text {stage }}}-N_{\text {obs, }_{\text {stage }}}\right)^{2}
$$

The model was iterated with different values for $\beta$ in Eq. (1) until a minimum SS value was achieved. A similar method was applied from CIII onwards but with modifications that allowed stage duration to be varied according to the phenotype of the animal (see 'Running the model').

Critical weight mortality: Voronina (1970) and Ward et al. (1997) suggested that spawning outside the main summer period was unlikely to produce recruits that will reach the later developmental stages since they will not survive the period of food shortage during winter. We applied this through assigning a high rate of mortality $\left(0.2 \mathrm{~d}^{-1}\right)$ to individuals that reached the CI stage after the last day of the productive period. For the bestestimate model run, we defined the productive period as 1 November to 28 February, based on Longhurst (1998), although the variability around these dates indicated by Korb et al. (2004) was built in to further sensitivity analyses. Individuals reaching CI after 28 February in the best-estimate model had a rapidly declining probability of surviving through the winter, such that $99.8 \%$ of individuals died within 1 mo.

Epipelagic mortality of late development stages: There are no estimates in the literature of mortality rates of late stage Rhincalanus gigas during the productive period, when the species inhabits the epipelagic layers. This reflects the difficulty of making such estimations with conventional methods. We cannot apply an SASM model, as in the case of the early stages, because stage durations vary according to lifecycle phenotype once an individual reaches stage CIII. Therefore, the rate of epipelagic mortality was varied alongside the proportion of different life-cycle phenotypes in the population as our model sought the best-fitting simulation of seasonal stage abundance (see 'Running the model').

Running the model: The best-estimate model was initialised with the smoothed observed annual stage abundances of $\mathrm{CI}$, as described above. Individuals spent $6 \mathrm{~d}$ (half the full stage duration to the nearest integer) in $\mathrm{CI}$ and $18 \mathrm{~d}$ in CII. The population was exposed to a mortality rate of $0.1 \mathrm{~d}^{-1}$ over this time.

The stage durations of the subsequent stages varied according to the life-cycle phenotype (Table 2). Shreeve (2002) determined that CIII lasted an average of $31 \mathrm{~d}$ when not in the overwintering stage. An approximation of $41 \mathrm{~d}$ was made for the stage duration of the non-overwintering CIV stage, based on unpublished observations (R. S. Shreeve; N = 480 CIV individuals). As overwintering stages, the durations of CIII and CIV were 240 and 199 d longer respectively, such that the moult to the next stage occurred around the start of the subsequent productive season. In the CV 1 yr phenotype, CV lasted $152 \mathrm{~d}$ so that the moult to adulthood occurred towards the end of their 1st winter. In CV 2 yr, individuals remained in this stage for $517 \mathrm{~d}$ (i.e. a whole year longer). The duration of $\mathrm{CV}$ was

Table 2. Rhincalanus gigas. Average durations (d) of developmental stages with respect to life-cycle phenotype. Most non-overwintering stage durations (i.e. those which are $41 \mathrm{~d}$ or less) are taken from Shreeve et al. (2002). The durations

\begin{tabular}{|c|c|c|c|c|c|}
\hline \multirow{2}{*}{$\begin{array}{l}\text { Developmental } \\
\text { stage }\end{array}$} & \multirow[b]{2}{*}{ CV 1 yr } & \multirow[b]{2}{*}{ CIII 2 yr } & \multirow{2}{*}{ Phenotype } & \multirow[b]{2}{*}{ CV 2 yr } & \multirow[b]{2}{*}{ CIII 3 yr } \\
\hline & & & & & \\
\hline $\mathrm{CI}^{\mathrm{a}}$ & 11 & 11 & 11 & 11 & 11 \\
\hline CII & 18 & 18 & 18 & 18 & 18 \\
\hline CIII & 31 & 271 & 31 & 31 & 271 \\
\hline CIV & 41 & 41 & 240 & 41 & 41 \\
\hline $\mathrm{CV}$ & 152 & 277 & 318 & 517 & 642 \\
\hline Adult & Infinite & Infinite & Infinite & Infinite & Infinite \\
\hline
\end{tabular}
of the overwintering stages (152 d or more) are inferred indirectly, as detailed in the text 
slightly shorter in CIII 2 yr and CIV 2 yr phenotypes ( 277 and $318 \mathrm{~d}$ respectively), given that these individuals did not enter this stage until the start of their 2nd year. All the 2 yr phenotypes entered adulthood towards the end of their 2 nd winter. The CIII 3 yr phenotype was assigned the same stage durations as the CIII 2 yr phenotype with the exception of stage CV, which was lengthened to $642 \mathrm{~d}$.

Seasonal abundance trajectories of all developmental stages beyond CI were predicted for all combinations of the 5 life-cycle phenotypes over a wide range of epipelagic mortalities. In initial runs, each phenotype was allowed to make up between 0 and $100 \%$ of the population (in 20\% increments) such that all phenotypes combined added up to $100 \%$. Epipelagic mortality rates were varied between the relatively wide limits of 0.003 and $0.018 \mathrm{~d}^{-1}$ (in increments $0.003 \mathrm{~d}^{-1}$ ) to ensure that the optimal value was bounded.

For each model run, the predicted seasonal abundance trajectories were compared with observations to determine their SS according to Eq. (3). The SS value was used to rank model runs to determine which phenotypic composition and epipelagic mortality rate produced the best fit to observations.

We found that high-ranking model runs contained: (1) no more than $60 \%$ of any one phenotype; (2) $0 \%$ of the CIII 3 yr phenotype; and (3) epipelagic mortality rates that were midway between the upper and lower limits. This information was used to parameterise a higher resolution model able to fit phenotypic composition and epipelagic mortality more precisely. For this model, the CIII 3 yr phenotype was excluded while all others could make up between 0 and $70 \%$ of the population in $10 \%$ increments. Mortality rate was varied between 0.005 and $0.011 \mathrm{~d}^{-1}$ in increments of $0.001 \mathrm{~d}^{-1}$. The mortality rates and phenotypic compositions of the top 20 ranked runs were extracted and analysed with descriptive statistics.

Sensitivity analyses. We tested the influence of variables that were fixed in the parameterisation of the best-estimate model. These included: (1) the early stage mortality rate, (2) the overwintering mortality rate, (3) the length of the epipelagic (productive) period, and (4) the prevailing temperature. Each of these parameters was increased and decreased to just beyond their expected limits, keeping all other parameters the same as in the best-estimate model, including the best-fitting life-cycle phenotype composition and epipelagic mortality rate. The SS value relative to that achieved by the best-estimate model was examined as a measure of the sensitivity of the model to that parameter.

\section{RESULTS}

\section{Population modelling}

The observed data set contained net catches from a number of different years and covered a large distributional range, so it is unsurprising that there was a degree of variability in stage abundance estimates at comparable times of year (Fig. 1). Fitting a model to such a data set ensures that the results are not biased by extreme conditions in any one particular year or subregion. However, it also runs the risk of being unable to discriminate between the suitability of different model solutions such that the choice of best-fitting variables becomes almost random. Evidence that the procedure was not prone to such a problem is given in Table 3 , where it

Table 3. Rhincalanus gigas. Top 20 combinations of life-cycle phenotypes and mortality rates with respect to the goodness-of-fit to observed stage abundance data for the 'high-resolution' model run (see 'Running the model'). Each phenotype was allowed to make up between 0 and $70 \%$ of the population in $10 \%$ increments, with the exception of the CIII $3 \mathrm{yr}$ phenotype, which had already been excluded by the 'low resolution' run. Mortality rates were varied between 0.005 and $0.011 \mathrm{~d}^{-1}$

\begin{tabular}{|c|c|c|c|c|c|}
\hline \multirow{2}{*}{ Rank } & \multirow{2}{*}{$\begin{array}{l}\mathrm{CV} 1 \mathrm{yr} \\
(\%)\end{array}$} & \multicolumn{2}{|c|}{ Phenotype - } & \multirow[b]{2}{*}{$\begin{array}{c}\text { CV } 2 \text { yr } \\
(\%)\end{array}$} & \multirow{2}{*}{$\begin{array}{l}\text { Epipelagi } \\
\text { mortality } \\
\text { rate }\left(\mathrm{d}^{-1}\right)\end{array}$} \\
\hline & & $\begin{array}{c}\text { CIII } 2 \text { yr } \\
(\%)\end{array}$ & $\begin{array}{c}\text { CIV } 2 \text { yr } \\
(\%)\end{array}$ & & \\
\hline 1 & 20 & 50 & 20 & 10 & 0.007 \\
\hline 2 & 30 & 50 & 20 & 0 & 0.008 \\
\hline 3 & 20 & 50 & 20 & 10 & 0.006 \\
\hline 4 & 20 & 50 & 30 & 0 & 0.007 \\
\hline 5 & 30 & 40 & 20 & 10 & 0.008 \\
\hline 6 & 10 & 50 & 20 & 20 & 0.005 \\
\hline 7 & 20 & 40 & 20 & 20 & 0.007 \\
\hline 8 & 10 & 50 & 20 & 20 & 0.006 \\
\hline 9 & 20 & 50 & 30 & 0 & 0.006 \\
\hline 10 & 30 & 50 & 20 & 0 & 0.009 \\
\hline 11 & 30 & 50 & 20 & 0 & 0.007 \\
\hline 12 & 20 & 60 & 20 & 0 & 0.007 \\
\hline 13 & 20 & 40 & 30 & 10 & 0.007 \\
\hline 14 & 20 & 50 & 20 & 10 & 0.008 \\
\hline 15 & 10 & 50 & 30 & 10 & 0.005 \\
\hline 16 & 30 & 40 & 20 & 10 & 0.009 \\
\hline 17 & 30 & 40 & 30 & 0 & 0.008 \\
\hline 18 & 20 & 40 & 20 & 20 & 0.006 \\
\hline 19 & 10 & 50 & 30 & 10 & 0.006 \\
\hline 20 & 20 & 50 & 30 & 0 & 0.008 \\
\hline Mean & 21 & 48 & 24 & 8 & 0.007 \\
\hline $\mathrm{SD}$ & 7 & 6 & 5 & 8 & 0.001 \\
\hline
\end{tabular}




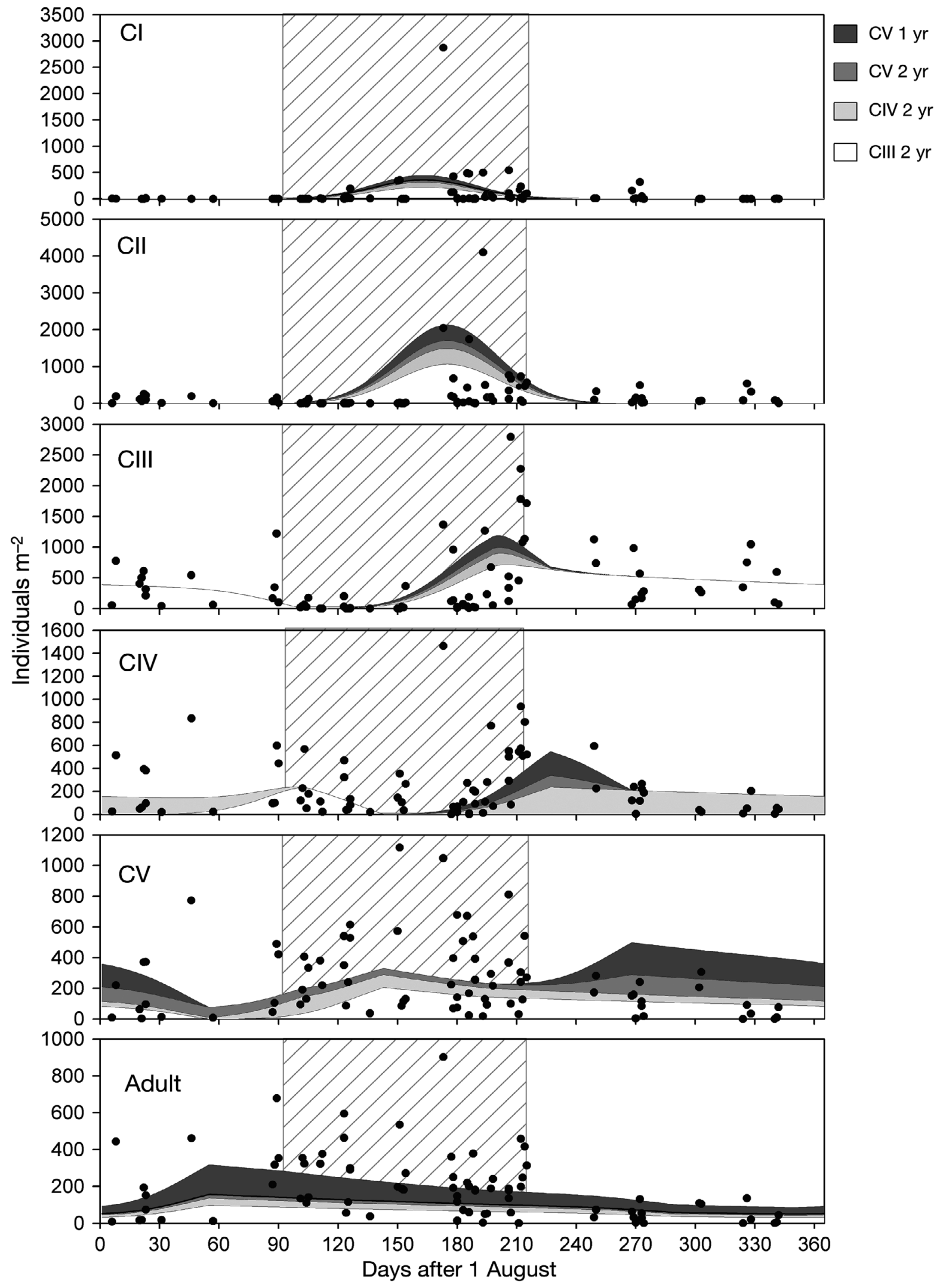

Fig. 1. Rhincalanus gigas. Predicted and observed abundance through the course of the year, starting from 1 August. Differently shaded areas depict the contributions of the respective life-cycle phenotypes determined by the best-estimate model. Points are the net-catch observed abundances. The shaded box between Days 93 and 212 represents the productive period (1 November to 28 February). Note the different scales on the $y$-axes 
can be seen that the best-fitting proportions of phenotypes and mortality rates are tightly clustered around certain values. Dominant phenotypes were clearly distinguished from those unlikely to be present at all.

\section{Life-cycle phenotype composition}

The model predicted that around half of the yearclass would be comprised of CIII 2 yr phenotype individuals (Table 3), which spend their 1st winter as a CIII and enter adulthood at the end of their 2 nd winter. No individual spending their 1st winter as a CIII took a further $2 \mathrm{yr}$ to enter adulthood, given the absence of the CIII 3 yr phenotype in the best-fitting compositions. Around a quarter of the year-class were predicted to be CIV 2 yr individuals while CV 2 yr made up less than $10 \%$ of the population. An average of $21 \%$ of individuals were predicted to get to adulthood within a year (CV $1 \mathrm{yr}$ ). The best-fitting mortality rate during the epipelagic period was $0.007 \mathrm{~d}^{-1}$.

The model was able to simulate many of the major features in the net-catch observations (Fig. 1). In CIII and CIV for instance, the model predicted that abundance peaked between 16 February (Day 200) and 8 March (Day 220), which is when net catches of these stages were highest. During the middle to late overwintering period ( 1 May, Day 274 to 1 October, Day $62)$, predicted abundances were about mid-way between net-catch abundances. The model predicted that there should be 2 peaks in the abundance of $C V$, one part way through the winter ( 27 Apr, Day 270) and the other in the middle of the productive period ( 18 Dec, Day 140). The former of these 2 peaks is a result of CV 1 yr phenotypes moulting from CIV to CV during their 1st winter, while the latter results from CIII 2 yr and CIV 2 yr phenotypes developing into CV in their 2 nd summer. The predicted midsummer peak corresponds to the period when some of the highest net-catch abundances of $\mathrm{CV}$ were observed. However, the winter peak occurs at a time when $\mathrm{CV}$ net-catch abundances are starting to fall.

The contribution of each life-cycle phenotype to the year-class as it develops towards adulthood is illustrated in Fig. 2. CIII 2 yr dominates the abundance of stage CIII for almost $400 \mathrm{~d}$ while CIV $2 \mathrm{yr}$ is the dominant phenotype in stage CIV abundance for around $350 \mathrm{~d}$. In CV, there is a double peak in abundance, the 1st around the start of April (Day 250), dominated by the CV 1 yr phenotype, and the 2nd around the middle of December (Day 500), where the 2 yr phenotypes are prominent. Particularly notable is that CV 1 yr makes up almost $40 \%$ of the $\mathrm{CV}$ population despite the fact that it originally only made $21 \%$ of the year-class. By adulthood, this proportion increases to $43 \%$. This trend is a result of these individuals experiencing about half of the mortality risk of the $2 \mathrm{yr}$ phenotypes by the time they reach the later developmental stages.

The predicted concentration and relative proportion of different developmental stages over the course of the year are presented in Figs. 3 \& 4 respectively. Between the start of April (Day 250) and middle of September (Day 50), the stage composition is relatively stable, with CIII dominating and CV making up a large part of the remainder. CIVs are much less abundant than the other 2 sub-adult stages, while adults make up only a minor part of the population at this time. The proportion of adults in the population increases in relative terms between early September (Day 50) and early November (Day 100), such that they eventually make up around $30 \%$ of the population. Their proportion then decreases as the main recruitment pulse arrives after the start of November (Day 100). Stage CIII and CIV start to disappear from the population around this time and only reappear in appreciable numbers after the middle of December (Day 140) after the main pulse of CI and CII individuals has started to decline.

\section{Mortality rate}

In the model, the Rhincalanus gigas population experienced different rates of mortality according to developmental stage and time of year. During the early developmental stages, the rate was set at $0.1 \mathrm{~d}^{-1}$, while during the later stages it switched between $0.007 \mathrm{~d}^{-1}$ in the epipelagic layers (during the productive period) and $0.003 \mathrm{~d}^{-1}$ in the deep (during winter). At such rates of mortality, around $80 \%$ of CI individuals died before reaching the end of their 1st year, while $96 \%$ perished before completing their 2nd year (Fig. 5). Nevertheless, around $1.5 \%$ (or 161 ind. $\mathrm{m}^{-2}$ ) of CI individuals were likely to make it beyond $3 \mathrm{yr}$, having spent either 1 or 2 yr as an adult.

\section{Sensitivity analyses \\ Early stage mortality}

The predictions of the model were most sensitive to alterations in the early stage mortality (Table 4). Decreasing this parameter from the best estimate of 0.1 to $0.02 \mathrm{~d}^{-1}$ had a particularly dramatic effect, making the goodness-of-fit (SS) worse by up to $6000 \%$. The model was less sensitive to increasing this parameter, with a doubling of the rate to $0.2 \mathrm{~d}^{-1}$ reducing the SS by around $50 \%$. Such findings emphasise the importance of early stage recruitment to the success or failure of a year-class. 


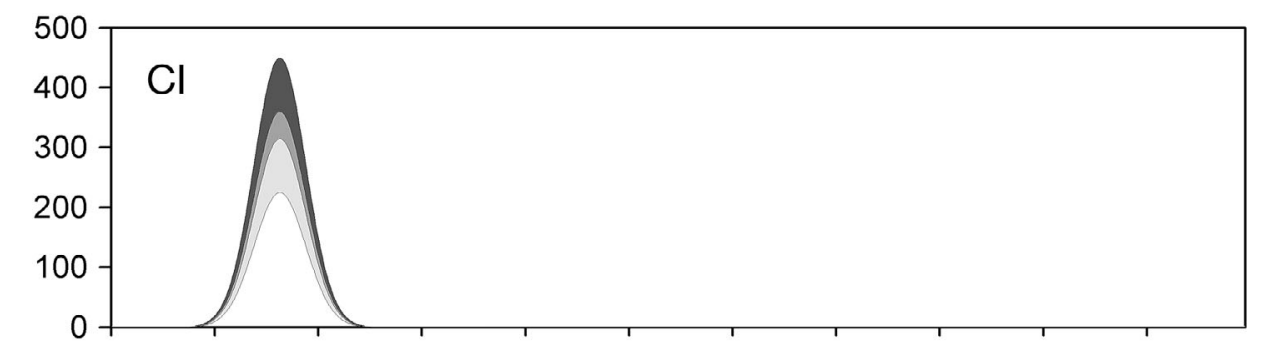

CV $1 \mathrm{yr}$
CV $2 \mathrm{yr}$
CIV $2 \mathrm{yr}$
CIII $2 \mathrm{yr}$
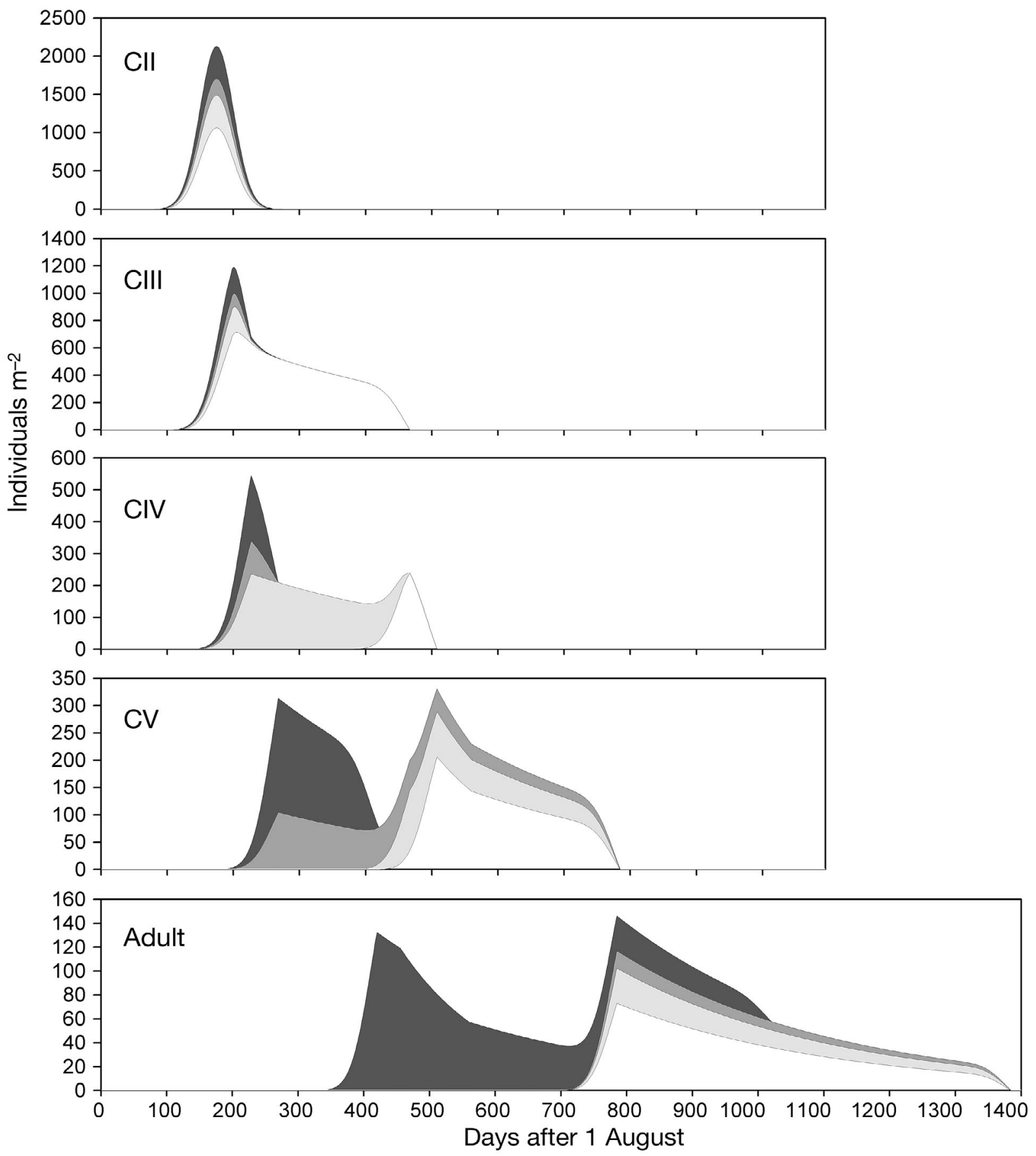

Fig. 2. Rhincalanus gigas. Predicted trajectory of stage abundance of a year-class over the course of its life-time. Differently shaded areas depict the contributions of the respective life-cycle phenotypes, determined by the best-estimate model 


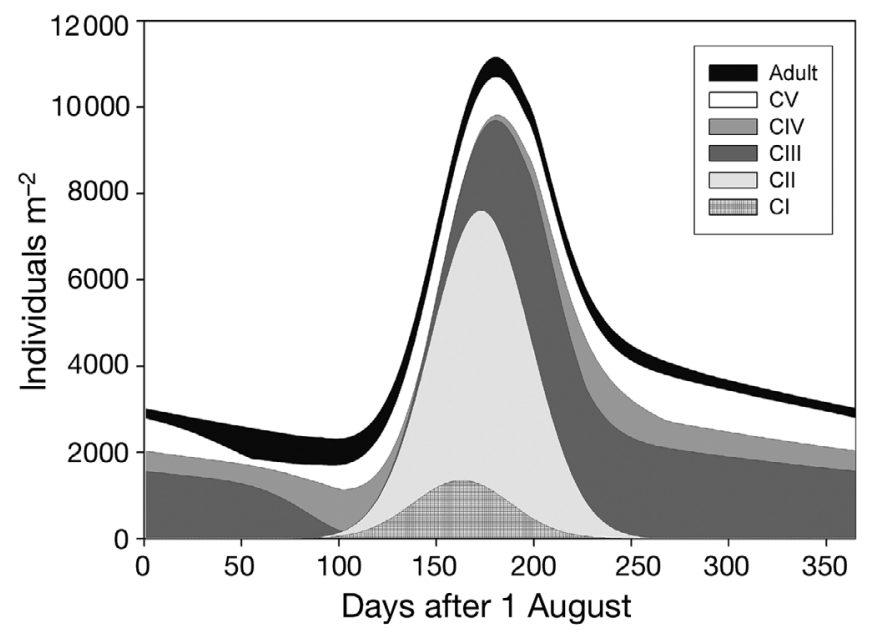

Fig. 3. Rhincalanus gigas. Predicted concentration (ind. $\mathrm{m}^{-2}$ ) of developmental stages from CI to adult over an annual cycle, derived from the results of the best-estimate model

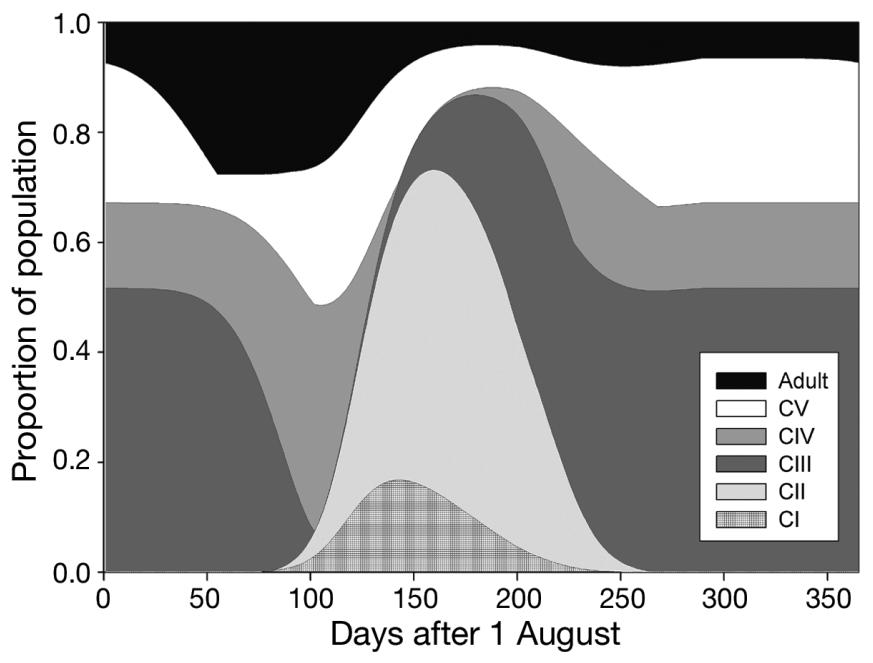

Fig. 4. Rhincalanus gigas. Relative proportion of different developmental stages from CI to adult over an annual cycle, derived from the results of the best-estimate model

\section{Overwintering mortality}

Sensitivity to changes in overwintering mortality rates increased with each subsequent developmental stage. Decreasing the rate from the best-estimate of $0.003 \mathrm{~d}^{-1}$ to $0.001 \mathrm{~d}^{-1}$ made around a $4 \%$ difference to the fit of all stages up to CIV, while increasing it to $0.005 \mathrm{~d}^{-1}$ had a similarly small effect. The later developmental stages are relatively more common during the overwintering period and so are more sensitive to this parameter. The above changes decreased the goodness-of-fit in the CV stages by $76 \%$ and in the adults by $662 \%$.
Length of the epipelagic (productive) period

Both increasing and decreasing the length of the epipelagic period made only a small difference to the relative goodness-of-fit, with the latter causing a stronger decrease $(17 \%)$ than the former (5\%). Changing this parameter alters the length of time the population is exposed to the higher epipelagic mortality rates versus the lower overwintering rates. The relative insensitivity to changes in these exposure levels reflects the fact that the difference between the 2 mortality rates is relatively small.

\section{Prevailing temperature}

It has long been known that copepod development rates are affected by variations in temperature (Mauchline 1998). We simulated this through altering stage durations in the model to those predicted at $0^{\circ} \mathrm{C}$ and $4^{\circ} \mathrm{C}$, the extremes of the temperature range experienced by this species in the Scotia Sea (Ward et al. 1997). The predictions were made using a Bělahrádek function (Bělahrádek 1935) for which Ward \& Shreeve (1998) derived 3 constants: a (shape of the regression), $\alpha$ (temperature scale position of the response) and $b$ (exponent) for the embryonic duration of Rhincalanus gigas. Using these constants, the development time of stage $i\left(D_{0}\right)$ at temperature $T_{0}$ was estimated for a known development time of stage $i\left(D_{1}\right)$ and temperature $T_{1}$ with the equation:

$$
D_{0}=D_{1}\left[\frac{a\left(T_{0}-\alpha\right)^{b}}{a\left(T_{1}-\alpha\right)^{b}}\right]
$$

Relative to the original model run at $2.2^{\circ} \mathrm{C}$, development times at $4^{\circ} \mathrm{C}$ decreased by $33 \%$ whereas, at $0^{\circ} \mathrm{C}$, they increased by $25 \%$. These changes decreased the level of fit by 75 and $29 \%$ respectively.

\section{DISCUSSION}

\section{Life-cycle phenotypes}

We found that there were likely to be 4 different lifecycle phenotypes co-existing in the Scotia Sea population of Rhincalanus gigas. The vast majority of these $(79 \%)$ reached adulthood in their 2nd year, of which most spent their 1st winter as stage CIII (CIII 2 yr). A minor component $(21 \%)$ became adults in their 1 st year, having reached stage CV before the start of their 1st winter (CV $1 \mathrm{yr}$ ). The best fitting mortality rate for stages beyond CII was $0.007 \mathrm{~d}^{-1}$ during the productive period, dropping to $0.003 \mathrm{~d}^{-1}$ during the winter. Exposure to these mortality rates meant that as many $\mathrm{CV}$ 


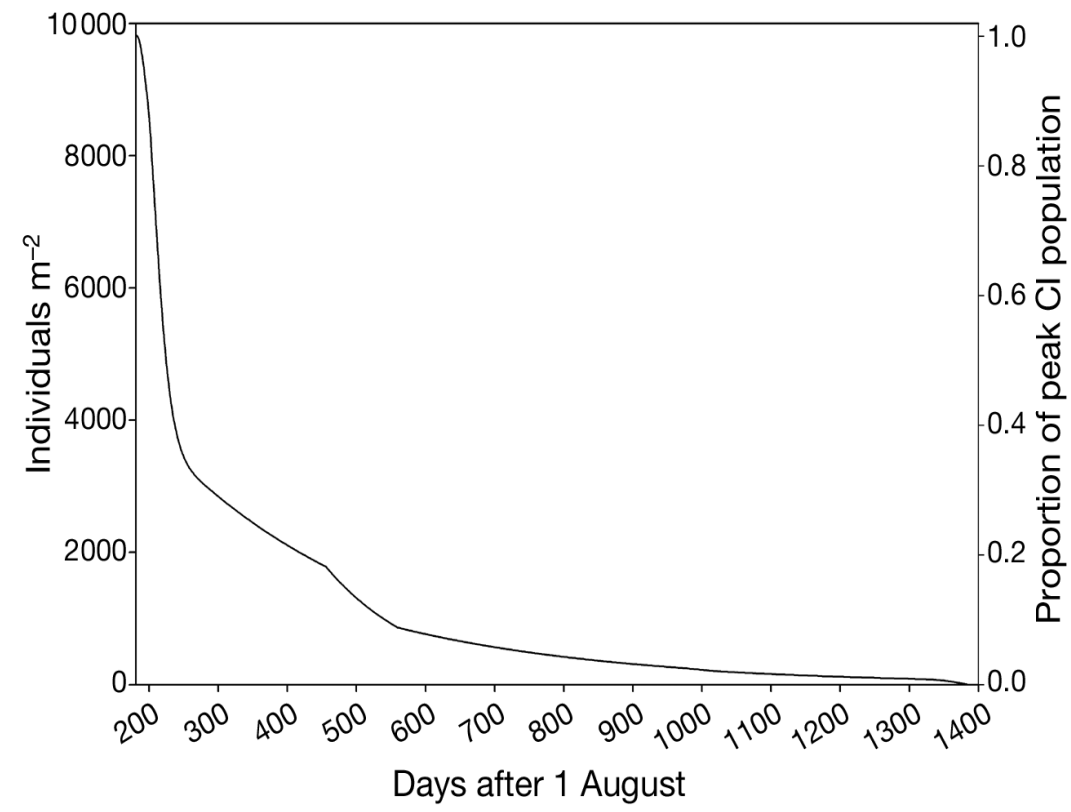

Fig. 5. Rhincalanus gigas. Predicted fate of the concentration of individuals (ind. $\mathrm{m}^{-2}$ ) in a year-class, from peak abundance in CI through to adulthood inferred by Ward et al. (1997), Ward \& Shreeve (1999) and Shreeve et al. (2002), with Ward et al. (1997) proposing that development from CIII to CIV, CIV to $\mathrm{CV}$, and $\mathrm{CV}$ to adulthood could all occur at this time. In fact, they observed that the moult from $\mathrm{CV}$ to adult only ever occurred during late winter and at no other time. This disagrees with Marin (1988), who believed that the moult from $\mathrm{CV}$ to adult could also occur at the end of the summer, producing a late-season generation. Interestingly, Ommaney (1936) believed that Rhincalanus gigas had a 6 mo life cycle given that there were 2 peaks in the abundance later stages within a 12 mo period. Our model reproduces such a pattern in the CV stage as a result of the different life-cycle phenotypes reaching this stage either before or after the winter period.
1 yr individuals made it to adulthood as all 2 yr phenotypes combined, even though the latter made up $79 \%$ of the original year-class.

Our findings on life-cycle phenotype composition generally agree with the qualitative assessments of Atkinson (1991) and of Ward et al. (1997). Both studies proposed that the population mainly reached either CIII or CIV by the end of the 1st productive period. Atkinson (1991) was unsure about when the moult to adulthood occurred and if any further moulting took place during the winter. Wintertime moulting was

\section{Overwintering}

Our model predicted 2 peaks in the abundance of $\mathrm{CVs}$, one in the summer and the other during the winter. The summertime peak corresponded to a period of increased net-catch abundances but the same was not true for the winter, where predicted abundances were generally higher than actual net-catches. Bias in the wintertime net-catch observations is a possible cause of this problem. It was assumed that the nets, which were deployed between 0 and $1000 \mathrm{~m}$, sampled the

Table 4. Rhincalanus gigas. Sensitivity analyses. Relative level of fit to observations compared with that of the best-estimate model (a negative value indicates a better fit; a positive value, a worse fit). Only the parameter indicated was changed in the sensitivity run; all other parameters were the same as in the best-estimate model, including the best-fitting life-cycle phenotype composition and epipelagic mortality rate

\begin{tabular}{|c|c|c|c|c|c|c|}
\hline \multirow[t]{2}{*}{ Parameter } & \multirow[b]{2}{*}{ CII (\%) } & \multirow[b]{2}{*}{ CIII $(\%)$} & \multicolumn{2}{|c|}{ - Developmental stage } & \multirow[b]{2}{*}{ Adult (\%) } & \multirow[b]{2}{*}{ Mean } \\
\hline & & & CIV $(\%)$ & $\mathrm{CV}(\%)$ & & \\
\hline \multicolumn{7}{|l|}{ Early stage mortality $\left(0.1 \mathrm{~d}^{-1}\right)$} \\
\hline Lower $\left(0.02 \mathrm{~d}^{-1}\right)$ & 772.62 & 2911.74 & 2164.58 & 5054.84 & 6057.47 & 3392.25 \\
\hline Higher $\left(0.2 \mathrm{~d}^{-1}\right)$ & -66.50 & 43.66 & 78.44 & 41.98 & 138.15 & 47.15 \\
\hline \multicolumn{7}{|c|}{ Overwintering mortality $\left(0.003 \mathrm{~d}^{-1}\right)$} \\
\hline Lower $\left(0.001 \mathrm{~d}^{-1}\right)$ & 0.00 & 0.75 & 4.08 & 76.44 & 661.73 & 148.60 \\
\hline Higher $\left(0.005 \mathrm{~d}^{-1}\right)$ & 0.00 & 0.75 & 4.08 & 76.44 & 661.73 & 148.60 \\
\hline \multicolumn{7}{|l|}{ Epipelagic period (103 d) } \\
\hline Longer (+50 d) & 0.00 & -0.08 & 11.81 & 14.96 & 0.02 & 5.34 \\
\hline Shorter $(-50 \mathrm{~d})$ & 0.00 & 15.90 & 25.07 & -2.75 & 46.73 & 16.99 \\
\hline \multicolumn{7}{|c|}{ Prevailing temperature $\left(2.2^{\circ} \mathrm{C}\right)$} \\
\hline Higher $\left(4^{\circ} \mathrm{C}\right)$ than average & 15.98 & 58.77 & 36.33 & 127.32 & 140.16 & 75.71 \\
\hline Lower $\left(0^{\circ} \mathrm{C}\right)$ than average & -14.24 & 14.57 & 57.39 & 14.22 & 75.09 & 29.41 \\
\hline
\end{tabular}


entire population. Like many polar calanoid species, Rhincalanus gigas makes a seasonal descent during the winter. Although it does not venture as deep as Calanoides acutus (Bathmann et al. 1993), it is conceivable that a certain fraction went below the maximum net depth of $1000 \mathrm{~m}$. This means that the real number of CVs in the population is higher than the wintertime net-catches indicate. Such a bias would result in the model overestimating the numbers between 0 and $1000 \mathrm{~m}$, since it is designed to determine the total abundance of the whole population, irrespective of vertical position in the water column.

The present study found that phenotypes which included some degree of wintertime moulting (CV $1 \mathrm{yr}$, CIV 2 yr, CV 2 yr) made up around half of the original year-class. The prevalence of moulting during winter indicates that this species remains relatively active during this time and does not enter true diapause. Several studies have indicated that Rhincalanus gigas is moderately active over winter. Pasternak et al. (1994) found that, unlike Calanoides acutus, $R$. gigas did not reduce its specific respiration rate when in the deeper layers during autumn. Hagen \& Schnack-Schiel (1996) found that there is little seasonal change in the amount of lipid stored by this species, and that its storage processes are relatively inefficient. They also found that there was a smaller weight loss over winter compared with true diapausing species such as $C$. acutus.

The above facts point to the likelihood that this species feeds during the winter period. Such active overwintering is relatively common amongst Antarctic copepod species, with many switching diets according to the season (Schnack-Schiel 2001). In a time of low primary productivity, this would mean having carnivorous or detrital feeding habits. Evidence of such items in the diet of Rhincalanus gigas have been found by Arashkevich (1978) and Pasternak \& Schnack-Schiel (2001), but more direct observations during winter are required.

\section{Spatial and temporal variability}

For the purpose of the model, we determined that the productive period started on 1 November and lasted until 28 February, based on the synthesis of a number of years of satellite-derived surface-chlorophyll data by Longhurst (1998). We estimated that the peak spawning of Rhincalanus gigas occurred around the start of November, given that the abundance of stage CI peaked around the middle of January, and egg hatching and naupliar development takes around $67 \mathrm{~d}$. However, the relative temporal spread of the CI population means that a large fraction of individuals would have been spawned before November. At first glance, this would imply that some $R$. gigas females spawn in advance of any primary productivity. However, this may not necessarily be the case.

Over the Scotia Sea, there is considerable variability around the start and end points of the productive season both spatially and inter-annually. Temporally, a productive season in this region may start as early as September and continue until the end of March, with several peaks and troughs in productivity in between (El-Sayed 1988, Korb et al. 2004). In other years, elevated productivity may be observed in December and January only (Korb et al. 2004). Spatially, the Scotia Sea is traditionally viewed as a high-nutrient lowchlorophyll environment, but the close vicinity of land masses and regions of ice-retreat are known to enhance levels of primary productivity (Brierley \& Thomas 2002, Korb \& Whitehouse 2004). Given the large temporal and spatial extent of our net-catch data set, it is likely that a number of data points were taken in years of high early productivity or from sites of enhanced local production. However, the aim of our model was to convey the average situation for the whole Scotia Sea and we considered such points as natural variability around the mean.

For many polar copepods, the exact timing of primary productivity events is not the most important determinant of when spawning takes place, because many utilise stored deposits of lipid. This does not appear to be the case for Rhincalanus gigas since it only maintains a limited lipid resource, and must rely on external resources in order to facilitate gonad development and egg production (Ward \& Shreeve 1995, Ward et al. 1996, Hagen 1999, Shreeve et al. 2002). Its spawning performance over the productive season appears to be protracted and sporadic (Atkinson 1991), probably because it responds to localised, short-lived events of primary productivity that can occur either side of as well as within the main productive season (Marin 1988, Marin \& Schnack-Schiel 1993, Hagen \& Schnack-Schiel 1996). Temperature is likely to be less influential than food in determining reproductive rates, as was the case for the congener Rhincalanus nasutus in the Benguela region (Richardson \& Verheye 1998).

\section{Mortality rate and lifespan}

Mortality rates $(\beta)$ during the productive period dropped from $0.1 \mathrm{~d}^{-1}$ in the early developmental stages to below $0.007 \mathrm{~d}^{-1}$ beyond stage CIII. During the overwintering period, it dropped further to $0.003 \mathrm{~d}^{-1}$ (Ward et al. 1997). Such rates are at the low extreme of rates predicted for other calanoid copepods (Hirst \& Kiørboe 2002). Rates of mortality are considered to be inversely 
proportional to body size (Mauchline 1998), which fits with Rhincalanus gigas being one of the largest calanoid copepods in the Southern Ocean. However, Kiørboe \& Sabatini (1995) contested the existence of such a pattern, positing that diel and ontogenetic behaviour as well as the occurrence and behaviour of predators have a large impact on such a trend.

We predicted that Rhincalanus gigas in the Scotia Sea matured to adulthood in its 1st or 2nd year. Given the above mortality rates, such individuals have a $35 \%$ chance of surviving $2 \mathrm{yr}$ as an adult. These individuals are most likely to be females, since Marin (1988) found females dominated the adult population as the season progressed. R. S. Shreeve (pers. obs.) noted the redevelopment of pre-existing ovaries in this species, which indicates they are capable of reproducing in more than 1 yr. Kosobokova (1999) noted such a pattern in the ovaries of Calanus glacialis in the White Sea.

Our prediction of a 3 to $4 \mathrm{yr}$ life-span makes Rhincalanus gigas one of the longest-lived copepod species in the Southern Ocean. Very few copepods are known to have multiyear life cycles in the Southern Ocean, but there are several species in the Arctic. In the subArctic Pacific, multiyear life cycles are exhibited by Neocalanus cristatus, N. plumchrus, and Eucalanus bungii (Miller et al. 1984). In Atlantic polar waters, Hirche (1997) proposed that Calanus hyperboreus did not reach adulthood until its 3rd year and lived for at least 1 yr more. Kosobokova (1999) posited that Calanus glacialis in the White Sea survives to a 4th year, although it matures to adulthood in its 2nd year. According to Conover \& Huntley (1991), polar copepods prioritise fecundity through waiting until they are large enough to spawn maximally, however long this takes. They believed that, for such species, entering another winter was probably not a great hardship. The comparative lack of long-lived copepods in the south may be because they do not reach the latitudinal extremes as observed in the north. This means that the productive season is relatively longer and the large size necessary to maximise fecundity can be achieved in a smaller number of years.

\section{Predation risk and behaviour}

The high biomass of Rhincalanus gigas (Ommaney 1936) makes it a key part of the Southern Ocean food web. It is a dietary item of the chaetoganths Eukrohnia hamata and Sagitta gazellae (Froneman et al. 1998) and fish such as myctophids and icefish (North \& Ward 1990). Birds, like prions (Pachyptila desolata, Reid et al. 1997a) and diving petrels (Pelecanoides urinatrix, Reid et al. 1997b) take them as alternative prey items when their favoured Antarctic krill are in short supply.
With so many potential predators, this species must minimise its risk of detection if it is to maintain a low mortality rate. Reducing movement is a primary means of achieving this. Shreeve (2002) observed that Rhincalanus gigas was relatively inactive during short-term incubations, hanging upside down in the water and periodically wiping their antennae on their mouth parts. Such behaviour is similar to that of Neocalanus cristatus, a long-lived sub-Arctic copepod that remains motionless for up to $90 \%$ of the time (Greene \& Landry 1988). N. cristatus survives through intercepting sinking particles, which it detects via its long antennae and tail plumes. Dagg (1993) estimates that this feeding behaviour could achieve a weight specific growth rate $(g)$ in excess of 0.02 at a standard rate of downward particle flux. Adopting a 'wait and intercept' type behaviour may be a feasible strategy for $R$. gigas also, given that large parts of the Scotia Sea are very productive (Korb et al. 2004) and downward particle flux high (Buesseler et al. 2005).

\section{Sensitivity analyses}

Our sensitivity analyses revealed that altering the level of mortality in the early stages caused the greatest influence on predicted stage abundance patterns. In the original parameterisation, we determined the value of this mortality through fitting a stage- and agestructured model to the CI and CII stage abundances. This approach gave us the mean amount of mortality occurring in these stages. It appears that changing this value by small amounts can make a large difference to the predicted abundances in all subsequent stages.

The stage durations provided by Shreeve et al. (2002) used in the original model were based on moult frequencies of CI to CV Rhincalanus gigas caught and incubated at an average temperature of $\sim 2^{\circ} \mathrm{C}$. This is the mid-point of the narrow temperature band in which most individuals of this species live (Ward et al. 1997). In our sensitivity analyses, stage durations were altered to those expected at the extremes of temperature experienced by this species, 0 and $4^{\circ} \mathrm{C}$. This did not greatly alter the fit of the model.

\section{Future perspectives}

Our modelling approach successfully reproduced the average stage abundance patterns of Rhincalanus gigas at the scale of the Scotia Sea. In so doing, it identified the major life-cycle phenotypes that are found in this region and predicted the rates of growth and mortality in different stages and at different times of the year. In carrying out this study, it was also evident that 
there was a large amount of variability in the net-catch observations. Such variability is likely to be the product of interannual and regional differences in environmental variables, such as phytoplankton concentration and the level of sea-ice cover, that affect survivorship and fecundity (Conover \& Huntley 1991, Ward \& Shreeve 1995, Ward et al. 1996, Shreeve et al. 2002). Our next challenge is to correlate stage-abundance patterns to these variables so that a predictive capability is generated. This will allow a better interpretation of the netcatch stage-abundances observed in any one year or research campaign. Furthermore, it will lead to an ability to predict how the population dynamics of this species would respond to future environmental changes.

We present here a case study objectively resolving the life-cycle pattern of arguably, the longest-lived copepod species in the Southern Ocean. The requirement to resolve complex population dynamic patterns is not limited to Rhincalanus gigas. The determination of reliable development, mortality and growth rates in long-lived species in the northern hemisphere is still a major objective. The complexity caused by the overlap of many yearclasses in such species remains one of the main obstacles to deriving such rates. Our fitting and ranking procedure is an objective and robust approach to this problem. Certain initial assumptions must be made in parameterising the model, particularly in establishing how many lifecycle phenotypes potentially co-exist in the population. However, these assumptions can be tested through sensitivity analyses and data confrontation. Furthermore, once fitted, the model has the potential to predict stage abundance patterns under various scenarios, such as the failure of particular year-classes (e.g. Miller et al. 1984). Our approach has the potential to make an important step in understanding the population dynamics of many long-lived calanoid copepods and we recommend its wider use.

Acknowledgements. We thank officers and crew of the RRS 'James Clark Ross' and our colleagues at BAS for their assistance in collection. This work was carried out for the FLEXICON project, a part of the BAS programme, Discovery 2010.

\section{LITERATURE CITED}

Arashkevich EG (1978) Some characteristics of feeding of copepods. Tr Inst Okeanol Akad Nauk SSSR 112:118-121

Atkinson A (1991) Life cycles of Calanoides acutus, Calanus simillimus and Rhincalanus gigas within the Scotia Sea. Mar Biol 109:79-91

Atkinson A (1994) Diets and feeding selectivity among the epipelagic copepod community near South Georgia in summer. Polar Biol 14:551-560

Atkinson A, Shreeve RS, Pakhomov EA, Priddle J, Blight SP, Ward P (1996) Zooplankton response to a phytoplankton bloom near South Georgia, Antarctica. Mar Ecol Prog Ser
144:195-210

Bathmann UV, Makarov RR, Spiridonov VA, Rohardt G (1993) Winter distribution and overwintering strategies of the Antarctic copepod species Calanoides acutus, Rhincalanus gigas and Calanus propinquus (Crustacea, Calanoida) in the Weddell Sea. Polar Biol 13:333-346

Brierley AS, Thomas DN (2002) Ecology of Southern Ocean pack ice. Adv Mar Bio 43:171-276

Buesseler KO, Andrews JE, Pike SM, Charette MA, Goldson LE, Brzezinski MA, Lance VP (2005) Particle export during the southern ocean iron experiment (SOFeX). Limnol Oceanogr 50:311-327

Bûlahrádek J (1935) Temperature and living matter. Protoplasma 8:1-277

Chojnacki J, Węglénska T (1984) Periodicity of composition, abundance and vertical distribtion of summer zooplankton (1977/78) in Ezcurra inlet, Admiralty Bay (King George Island, South Shetland). J Plankton Res 6:997-1017

Conover RJ, Huntley M (1991) Copepods in ice-covered seas - distribution, adaptations to seasonally limited food, metabolism, growth patterns and life cycle strategies in polar seas. J Mar Syst 2:1-41

Dagg M (1993) Sinking particles as a possible source of nutrition for the large calanoid copepod Neocalanus cristatus in the sub-Arctic Pacific-Ocean. Deep-Sea Res I 40:1431-1445

Dagg MJ, Urbanrich J, Peterson JO (2003) The potential contribution of fecal pellets from large copepods to the flux of biogenic silica and particulate organic carbon in the Antarctic Polar Front region near 170 degrees W. DeepSea Res II 50:675-691

El-Sayed SZ (1988) Seasonal and interannual variabilities in Antarctic phytoplankton with reference to krill distribution. In: Sahrhage D (ed) Antarctic ocean resources and variability. Springer-Verlag, Berlin, p 101-119

Froneman PW, Pakhomov EA, Perissinotto R, Meaton V (1998) Feeding and predation impact of 2 chaetognath species, Eukrohnia hamata and Sagitta gazellae, in the vicinity of Marion Island (Southern Ocean). Mar Biol 131:95-101

Graeve M, Hagen W, Kattner G (1994) Herbivorous or omnivorous - on the significance of lipid compositions as trophic markers in Antarctic copepods. Deep-Sea Res I 41: 915-924

Greene CH, Landry MR (1988) Carnivorous suspension feeding by the sub-Arctic calanoid copepod Neocalanus cristatus. Can J Fish Aquat Sci 45:1069-1074

Hagen W (1999) Reproductive strategies and energetic adaptations of polar zooplankton. Invertebr Reprod Dev 36:25-34

Hagen W, Schnack-Schiel SB (1996) Seasonal lipid dynamics in dominant Antarctic copepods: energy for overwintering or reproduction? Deep-Sea Res I 43:139-158

Hart RC (1990) Copepod post-embryonic durations: pattern, conformity, and predictability. The realities of isochronal and equiproportional development, and trends in the copepod-naupliar duration ratio. Hydrobiologia 206: $175-206$

Hirche HJ (1997) Life cycle of the copepod Calanus hyperboreus in the Greenland sea. Mar Biol 128:607-618

Hirst AG, Kiørboe T (2002) Mortality of marine planktonic copepods: global rates and patterns. Mar Ecol Prog Ser 230:195-209

Kiørboe T, Sabatini M (1995) Scaling of fecundity, growth and development in marine planktonic copepods. Mar Ecol Prog Ser 120:285-298

Korb RE, Whitehouse M (2004) Contrasting primary production regimes around South Georgia, Southern Ocean: 
large blooms versus high nutrient, low chlorophyll waters. Deep-Sea Res I 51:721-738

Korb RE, Whitehouse MJ, Ward P (2004) SeaWiFS in the southern ocean: spatial and temporal variability in phytoplankton biomass around South Georgia. Deep-Sea Res II 51:99-116

Kosobokova KN (1999) The reproductive cycle and life history of the Arctic copepod Calanus glacialis in the White Sea. Polar Biol 22:254-263

Longhurst A (1998) Ecological geography of the sea. Academic Press, London

Mackintosh NA (1937) The seasonal circulation of the Antarctic macroplankton. Discor Rep 16:365-412

Marin V (1988) Qualitative models of the life-cycles of Calanoides acutus, Calanus propinquus, and Rhincalanus gigas. Polar Biol 8:439-446

Marin VH, Schnack-Schiel SB (1993) The occurrence of Rhincalanus gigas, Calanoides acutus, and Calanus propinquus (Copepoda, Calanoida) in late May in the area of the Antarctic Peninsula. Polar Biol 13:35-40

Mauchline J (1998) The biology of calanoid copepods. Adv Mar Biol 33

Miller CB, Frost BW, Batchelder HP, Clemons MJ, Conway RE (1984) Life histories of large, grazing copepods in a subArctic ocean gyre - Neocalanus plumchrus, Neocalanus cristatus, and Eucalanus bungii in the northeast Pacific. Prog Oceanogr 13:201-243

North AW, Ward P (1990) The feeding ecology of larval fish in an Antarctic fjord, with emphasis on Champoscephalus gunnari. In: Kerry KR, Hempel G (eds) Antarctic ecosystems: ecological change and conservation. SpringerVerlag, Berlin, p 299-307

Ommaney FD (1936) Rhincalanus gigas (Brady) a copepod of the Southern Ocean macroplankton. Disc Rep 13:231-334

Pakhomov EA, Froneman PW, Perissinotto R (2002) Salp/krill interactions in the Southern Ocean: spatial segregation and implications for the carbon flux. Deep-Sea Res II 49: 1881-1907

Pasternak AF, Schnack-Schiel SB (2001) Feeding patterns of dominant Antarctic copepods: an interplay of diapause, selectivity, and availability of food. Hydrobiologia 453: 25-36

Pasternak AF, Kosobokova KN, Drits AV (1994) Feeding, metabolism and body composition of the dominant Antarctic copepods with comments on their life cycles. Russ J Aquat Ecol 3:49-62

Reid K, Croxall JP, Edwards TM (1997a) Interannual variation in the diet of the Antarctic Prion Pachyptila desolata at South Georgia. EMU 97:126-132

Reid K, Croxall JP, Edwards TM, Hill HJ, Prince PA (1997b)

Editorial responsibility: Howard Browman (Associate Editorin-Chief), Storebø, Norway
Diet and feeding ecology of the diving petrels Pelecanoides georgicus and P. urinatrix at South Georgia. Polar Biol 17:17-24

Richardson AJ, Verheye HM (1998) The relative importance of food and temperature to copepod egg production and somatic growth in the southern Benguela upwelling system. J Plankton Res 20:2379-2399

Schnack SB, Smetacek V, von Bodungen B, Stegmann P (1985) Utilization of phytoplankton by copepods in Antarctic waters during spring. In: Gray JS, Christiansen ME (eds) Marine biology of polar regions and effects of stress on marine organisms. John Wiley \& Sons, Chichester, p 65-81

Schnack-Schiel SB (2001) Aspects of the study of the life cycles of Antarctic copepods. Hydrobiologia 453:9-24

Shreeve RS (2002) Growth of 2 species of Southern Ocean copepod in relation to their environment. $\mathrm{PhD}$ thesis, Open University, Milton Keynes

Shreeve RS, Ward P, Whitehouse MJ (2002) Copepod growth and development around South Georgia: relationships with temperature, food and krill. Mar Ecol Prog Ser 233: 169-183

Suzuki H, Sasaki H, Fukuchi M (2003) Loss processes of sinking fecal pellets of zooplankton in the mesopelagic layers of the antarctic marginal ice zone. J Oceanogr 59: 809-818

Tarling GA, Shreeve RS, Ward P, Atkinson A, Hirst AG (2004) Life-cycle phenotypic composition and mortality of Calanoides acutus (Copepoda: Calanoida) in the Scotia Sea: a modelling approach. Mar Ecol Prog Ser 272: 165-181

Voronina NM (1970) Seasonal cycle of some common Antarctic copepod species. In: Holdgate NM (ed) Antarctic ecology. Academic Press, London, p 162-172

Ward P, Shreeve RS (1995) Egg-production in 3 species of Antarctic calanoid copepods during an austral summer. Deep-Sea Res I 42:721-735

Ward P, Shreeve R (1998) Egg hatching times of Antarctic copepods. Polar Biol 19:142-144

Ward P, Shreeve RS (1999) The spring mesozooplankton community at South Georgia: a comparison of shelf and oceanic sites. Polar Biol 22:289-301

Ward P, Shreeve RS, Cripps GC (1996) Rhincalanus gigas and Calanus simillimus: lipid storage patterns of two species of copepod in the seasonally ice-free zone of the Southern Ocean. J Plankton Res 18:1439-1454

Ward P, Atkinson A, Schnack-Schiel SB, Murray AWA (1997) Regional variation in the life cycle of Rhincalanus gigas (Copepoda: Calanoida) in the Atlantic sector of the Southern Ocean - re-examination of existing data (1928 to 1993). Mar Ecol Prog Ser 157:261-275

Submitted: October 19, 2005; Accepted: October 18, 2006

Proofs received from author(s): April 26, 2007 